\title{
Getting a joke: the time course of meaning activation in verbal humor
}

\author{
Jyotsna Vaid ${ }^{\mathrm{a}, *}$, Rachel Hull ${ }^{\mathrm{a}}$, Roberto Heredia ${ }^{\mathrm{b}}$, \\ David Gerkens ${ }^{\mathrm{a}}$, Francisco Martinez ${ }^{\mathrm{a}}$ \\ ${ }^{a}$ Department of Psychology, Texas A\&M University, College Station, TX 77843-4235, USA \\ ${ }^{\mathrm{b}}$ Department of Psychology, 5201 University Boulevard, Texas A\&M International University, \\ Laredo, TX 78041-1900, USA
}

Received 7 September 2002; received in revised form 16 November 2002

\begin{abstract}
Two lexical decision semantic priming experiments examined when, in the course of reading a joke, the initial and the intended meanings are primed; whether the meanings overlap in time; and what happens to the initial reading when the punchline is encountered. In Experiment 1, probes related to the first activated sense (S1) vs. the second sense (S2), or true meaning, were presented at each of three temporal sites for visually displayed joke tests: shortly after joke onset, at an intermediary position, and at punchline offset, whereas in Experiment 2, probes were presented at joke offset following prolonged viewing. The results from Experiment 1 showed S1 priming effects at the initial and intermediary time point. Priming for S2 also emerged at the intermediary time point and persisted at the final time point. In Experiment 2, the priming effect at joke offset was reliable only for S2. The results are taken to support a concurrent meaning activation view [in line with Attardo, Humor 10 (1997) 395] at incongruity detection, and a selective activation view [in line with Giora, Journal of Pragmatics 16 (1991) 465] at incongruity resolution.
\end{abstract}

(C) 2002 Elsevier Science B.V. All rights reserved.

Keywords: Jokes; Humor; Incongruity; Ambiguity; Time course

\section{Introduction}

Whereas much of normal discourse is potentially ambiguous, the ambiguity in most instances is usually minimized through the use of disambiguating cues provided by

* Corresponding author.

E-mail address: jxv@psyc.tamu.edu (J. Vaid). 
the context. In contrast, jokes are an example of what Kittay (1987) has called purposive ambiguity. In such instances, words are not intended to have only a single meaning and the context-congruent meaning turns out to have very little to do with the true meaning of the joke. In fact, as Nerlich and Clarke (2001) point out, it is remarkable how much of daily linguistic interaction is structured by a play with multiple meanings.

Playing with multiple meanings is a critical ingredient of jokes, which typically set up an opposition between two disparate meanings. In his treatise on creativity, Koestler (1964) argued that humor involves bisociative thinking, which he defines as perceiving a situation in terms of two self-consistent but totally incompatible frames of reference. Indeed, incongruity is commonly agreed by humor theorists (e.g., Suls, 1972) to be a necessary (if perhaps not sufficient) criterion for an utterance or an event to be perceived as funny (see Vaid and Ramachandran, 2001).

The first and still leading application of script/frame/schema theory to humor was developed by Victor Raskin (1985) and formed the basis for subsequent cognitively oriented frameworks of humor processing (e.g., Attardo and Raskin, 1991; Norrick, 1986; Veatch, 1998). Norrick recast the bisociative analysis of humor in frame theoretic terms, proposing that jokes first evoke and then skew a schema. Joke perception is said to require that the perceiver first recognize a schema (or a script, in Attardo and Raskin's, 1991 framework) and then reinterpret it in the face of the conflict created by information that is inconsistent with the original schema. This reinterpretation process, which has also been described as incongruity resolution (Suls, 1972) or frame-shifting (Coulson, 2001), is seen as critical to the enjoyment of humor.

Cognitively oriented accounts of humor have, thus, posited distinct stages of information processing in joke comprehension (Attardo, 1997; Suls, 1972). There is an initial set up phase, which lays the groundwork for the incongruity by instantiating an initial schema and a meaning consistent with that schema. In the second phase (incongruity discovery), the expectancy created by the initial schema is violated. Finally, in the third (resolution) phase, the conflict created by the expectancy violation is reduced by a reinterpretation of the joke in terms of an alternate, higher level schema in which the joke makes sense in light of the new information presented in the joke's punchline.

The various theoretical accounts of humor concur in positing abrupt shifts in the particular meanings or scripts activated in the course of comprehending a joke. Yet surprisingly little empirical research exists on the time course of meaning activation in joke processing. Attardo (1997: 416) notes that, aside from claiming "that the onset of the incongruity must be sudden, or that the simultaneous consideration of the two opposed scripts must be brief" most theories of humor "have little to say about timing',

The present research was conducted to redress this gap. The questions addressed concern when each reading of a joke becomes accessible to awareness, whether the two readings overlap in time, and what happens to the initial reading once the punchline meaning is encountered. Using a lexical decision semantic priming procedure, the research operationalized and tested two conceptualizations of joke perception, with 
differing implications for the time course of multiple meaning activation in humor. We first summarize these two conceptualizations, termed the concurrent activation and the selective activation views.

\subsection{Concurrent activation view}

This view has its origins in the script opposition model of verbal humor, developed by Attardo and Raskin (1991) and subsequently elaborated by Attardo (1997) in terms of a three-stage model of humor processing (the stages being Setup-Incongruity-Resolution, or SIR). In this view, humor is defined as a semantic opposition between differing scripts, where scripts refer to collections of semantic information on a given subject that embody the sum of cultural knowledge and are represented as a set of expectations and/or weighted choices. Attardo notes that, to the extent that joke texts being linear are subject to temporal ordering, scripts presented earlier become part of the context and establish a framework of expectations against which scripts occurring later are to be processed (Attardo, 1997: 403). However, the two competing scripts must in some sense coexist temporally in the mind of the humor comprehender. This coexistence is needed at the incongruity phase, Attardo notes, "for the time necessary to the evaluation of the dissimilarity between the expected and the observed data" (p. 412). Coexistence is also needed at the resolution phase, where "the two interpretations must be conserved in 'working memory' for a certain period of time necessary for the research of a cognitive rule capable of solving the incongruity" (Attardo, 1997: 412).

Consistent with this view, Nerlich and Clarke (2001) suggest that humorous uses of incongruity are examples of an 'ambiguated' use of context in which language is kept alive by "keeping several meanings of a word or expression in mind simultaneously" (p. 9). They refer to research that shows that understanding of polysemous words results in the continued activation of inappropriate senses for some time after the word has been encountered.

\subsection{Selective activation view}

A somewhat different formalization of humor is presented by Giora (1991), who offers two criteria for successful or well-formed jokes involving semantic ambiguity (rather than syntactic or pragmatic violations). The first criterion is a marked informativeness requirement. Giora notes that all texts involve a progressive increase in informativeness. In non-joke texts this increase is held to progress gradually. In joke texts, however, the increase occurs suddenly and abruptly and involves a shift from an initial unmarked to a final marked meaning of the text. Giora's second criterion for well-formedness of jokes is that the joke "...causes the reader to perform a linear shift: the reader is made to cancel the first unmarked interpretation upon processing the second marked interpretation," (Giora, 1991: 470).

While the exact timing of this linear shift is not specified, what is important to note here is the claim that, once processed (i.e., upon resolution of the joke), the true 
joke meaning has the effect of erasing the impact of the original reading of the joke text. Indeed, Giora asserts that the canceling of the original reading is what makes a joke funny: "where ambiguity is not cancelled but sustained, the effect is witty but not funny," (Giora, 1991: 476).

Colston et al. (2000 as cited in Giora, in press) go so far as to suggest that the initial reading of the joke text is actually suppressed once the joke's actual meaning is realized. Consistent with this view, Coulson and Kutas (2001) propose that a semantic reinterpretation process characterizing joke processing is facilitated if aspects of the initial interpretation are suppressed in working memory.

On the basis of the above theoretical positions, two complementary predictions about meaning activation during joke processing may be put forth. The position associated with Attardo (1997) would predict that both the first activated sense of the joke (S1); what we also refer to below as the 'favored' meaning), and the second activated sense (S2); (or the surprising, true joke meaning) should be concurrently (and perhaps even simultaneously) activated as early as at incongruity discovery, but certainly by the time of incongruity resolution. Giora (1991) would predict that S1 should be less active than S2 and that S1 would perhaps even be suppressed upon joke resolution.

\section{The present research}

The present research was conducted as an empirical test of these two predictions. Lexical decision reaction times (RT) taken at different points during the reading of a joke text were used to determine whether and at what specific time point a target word related to either the favored or the surprising meaning would be semantically primed, and whether the priming occurs gradually or abruptly.

Two experiments were conducted. In the first experiment, probes related to S1 (the favored meaning) vs. S2 (the surprising meaning) were presented at three discrete temporal points in joke texts: immediately after the joke was introduced (i.e., during joke setup), at an intermediate point in the joke text when information discrepant with the initial reading is introduced (i.e., during the incongruity phase), and immediately after the onset of the punchline (in the resolution phase). Baseline response times were measured by presenting target words prior to joke onset. The differences in response time (RT) between baseline responses and responses at each of the three temporal sites allowed for a comparison of the size of priming effects. The second experiment explored the fate of S1 after punchline offset (i.e., postresolution), using a slightly different priming procedure, in which lexical decision RTs to targets related to the favored vs. surprising meaning were compared relative to semantically neutral controls.

\subsection{Experiment 1}

This experiment addressed two issues: (1) whether the shift from the initial sense to the joke reading of the text occurs gradually or abruptly, and (2) whether the 
initial (S1) and joke readings (S2) are concurrently or selectively primed at or beyond the incongruity stage.

The working hypotheses for the rate of meaning activation were as follows:

(a) If the activation of the joke meaning occurs gradually, one would expect a progressively increased activation for $\mathrm{S} 2$ over the three time points, i.e., from setup to incongruity and from incongruity to resolution.

(b) If joke meanings involve a sudden frame shift, there should be no priming of the $\mathrm{S} 2$ at setup and a high level of priming of $\mathrm{S} 2$ at incongruity, which should persist at resolution.

The working hypotheses regarding the time course of meaning activation during verbal humor processing were as follows:

(a) Concurrent activation will be evidenced by equivalent priming of S1 and S2 as early as the incongruity stage and upon presentation of the punchline.

(b) Sequential activation will be evidenced by selective priming of S1 at setup, followed by selective priming of S2 at the incongruity stage and at punchline onset.

\subsubsection{Method}

2.1.1.1. Pretesting. To select favored vs. surprising meaning associates for joke texts, a sample of 30 college undergraduates were asked to read each of eight jokes. For each joke, they were to report the meaning that first came to mind upon reading the first line of the joke, and the meaning that first occurred to them upon reading the last line of the joke. The responses were coded based on the output dominant meaning, i.e., the meaning mentioned by the largest number of participants for each of the two joke lines, initial and final. These were used in the selection of experimental stimuli for the favored (S1) and surprising (S2) joke meaning conditions, respectively.

2.1.1.2. Participants. Experimental participants were 80 college undergraduates from a large southwestern university. Participants received course credit for their participation. They were tested in small groups of up to 20. Responses from 17 participants who failed to complete the task were dropped.

2.1.1.3. Apparatus. The experiment was carried out on 20 computers using the Netscape Navigator 4.7 browser, JavaScript enabled. The computers recorded participants' response times and streamed them through a Common Gateway Interface (CGI) program that separated each form entry into an individual participant text file accessible only to the experimenters. Participants were seated in front of color monitors. Jokes were presented one line at a time in the center of the screen followed by a target word or nonword. Participants were to press one of two designated keys for "yes" and "no" responses on the lexical decision task. The target or nonsense letter strings were presented in the same location on the screen as the jokes. 
Table 1

Experiment 1. Sample joke text and probes

\begin{tabular}{|c|c|c|}
\hline Joke stage & Line of joke text & Possible probes \\
\hline Baseline (T1) & Prior to joke text ${ }^{\mathrm{a}}$ & \\
\hline Setup (T2) & "Woman walks into bar with duck on leash."a & $\begin{array}{l}\text { favored = "PET" OR } \\
\text { surprising }=" \mathrm{SOW} \mathrm{W}^{\prime \prime} \underline{\mathrm{OR}}\end{array}$ \\
\hline Incongruity (T3) & $\begin{array}{l}\text { "Bartender says, 'Where'd you get the pig?' } \\
\text { Woman says, 'This is not a pig; it's a duck!', }\end{array}$ & $\begin{array}{l}\text { nonsense } 1=\text { "ITE" } \underline{\mathrm{OR}} \\
\text { nonsense } 2=\text { "'OPE" }\end{array}$ \\
\hline Resolution (T4) & "Bartender says, 'I was talking to the duck." "a & \\
\hline
\end{tabular}

Participant receives each line of text followed by ONE associated probe for lexical decision; no probe is repeated once it has appeared for a given participant.

a Indicates the point at which probes appeared.

2.1.1.4. Materials and design. To familiarize them with the task requirements without actually presenting jokes during the practice session, participants were presented with lines from a poem (excerpts from Shel Silverstein's "Where the Sidewalk Ends"), one line at a time. They practiced reading the text and making lexical decision judgments to target stimuli following each line. For the study proper, participants were randomly assigned to one of two conditions - favored or surprising. Each condition involved an identical set of eight joke texts. In the favored condition, the lexical decision targets presented were semantically related to the initially favored interpretation (S1) of the joke (as determined in the pretest), whereas the surprising condition offered lexical decision targets that were related to the true joke meaning (S2) (see Table 1).

The joke texts were presented in upper-and lowercase letters, one line at a time, in segments that corresponded to the three component stages of setup (line 1), incongruity (line 2 or 3 ), and resolution (final line). ${ }^{1}$ Lexical decision targets per joke appeared $2500 \mathrm{~ms}$ after the onset of one of the joke lines or prior to the first line (i.e., baseline time point). To encourage actual reading of the lexical decision stimuli rather than relying on guesswork, participants were instructed to subvocalize the target stimuli (as well as the joke texts). Target stimuli were presented in capital letters to distinguish them from joke text lines. Participants used the ' $\mathrm{C}$ ' or ' $\mathrm{B}$ ' keys (labeled 'word' or 'nonword') to make a lexical decision about each probe, and a JavaScript program recorded response times in milliseconds from onset of the probe until one of the keys was pressed. After each lexical decision trial, participants were to click the 'start' button or press the 'enter' key to proceed to the next joke.

Each joke was associated with four possible choices for its lexical decision task, namely: (1) the favored, or S1, meaning, (2) a pronounceable nonword matched in length, (3) the surprising, or S2, meaning, or (4) its matched nonword. The targets

1 Based on average reading times collected from pilot testing $(n=300)$, the inter-stimulus interval was set at $2500 \mathrm{~ms}$. 
were presented in a fixed random order such that, across participants, each target was represented equally at each time point, and there was an equal chance of receiving an actual target or a nonsense word.

2.1.1.5. Data analysis. A mixed, within-subjects $2 \times 3$ factorial design ANOVA was used to analyze the response time data matrix of Probe Type (S1 vs. S2) and Time Point in the joke (setup, incongruity, resolution). Mean RTs were calculated across participants for each probe type at each of the time points (including the baseline), and difference scores were obtained. That is, the mean baseline RT for each probe type was subtracted from the mean RT at each of the three time points within the joke text. ${ }^{2}$ The two factor ANOVA compared the difference scores for the S1 vs. S2 targets (between subjects variable) at each of the three time points in the joke texts (within subjects variable) to determine whether the RTs at a given time point differed significantly from any other. Paired t-tests were used to determine which difference scores varied significantly from the baseline. Finally, t-tests for independent samples were used to compare whether the difference scores for S1 targets were significantly different from those of S2 targets at each experimental time point.

\subsubsection{Results and discussion}

The analysis of variance revealed no interaction of time and probe type $[F(2,122)$ $=1.82$, n.s.] but there was a main effect of time $[F(2,122)=16.05, P<0.0001)]$. In light of our a priori hypotheses, the data for the three time points were subsequently examined separately per probe type.

For targets related to S1, paired-t tests showed a significant priming effect at the initial time point $[t(31)=2.21, P<0.035]$ and at the intermediary time point $[t(35)=4.04, P<0.0003]$, but not at the final time point $[t(33)=1.38$, n.s.]. That is, immediately following presentation of the joke punchline, the non-joke meaning was no longer primed relative to baseline as it had been at time periods corresponding to setup and incongruity phases.

For targets related to $\mathrm{S} 2$, by contrast, paired $t$-tests indicated no priming effects during setup $[t(32)=0.86$, n.s.] or at resolution $[t(36)=1.36$, n.s.], nor were these two priming levels different from each other. That is, no priming effect relative to baseline was found for true joke meanings either at the beginning or at the end of jokes. However, RTs to S2 were significantly faster than baseline at intermediary time points $[t(37)=5.26, P=0.0001]$. In other words, a significant priming effect was detected for joke meaning targets only during the incongruity stage of joke processing. Moreover, for both S1 and S2, the size of the priming effect was fairly high at the intermediary time point. Independent sample $t$-tests on relative priming by target type revealed a significant difference in priming level only at the setup stage: greater priming was observed for S1 relative to S2 meanings $[t(63)=2.21, P<0.05]$. S2 and S1 targets showed an equivalent level of priming at intermediary and final time points. However, the amount of priming of each target type at the final time point

\footnotetext{
${ }^{2}$ RTs to incorrect lexical judgments and those longer than $2000 \mathrm{~ms}$ or shorter than $200 \mathrm{~ms}$ were excluded from the analyses.
} 
was markedly lower than that at the intermediary point. Specifically, S1 targets dropped from a mean difference score ${ }^{3}$ of $189.4 \mathrm{~ms}$ at incongruity to $78.2 \mathrm{~ms}$ at resolution, while S2 targets dropped from a mean of $253.4 \mathrm{~ms}$ at incongruity to 66.0 $\mathrm{ms}$ at resolution (Fig. 1). The difference scores for the two target types did not significantly deviate from each other either at incongruity or resolution.

In summary, our results indicate that non-joke interpretations are primed during the joke setup and the incongruity periods, whereas true joke interpretations become primed only during the incongruity stage. Moreover, both non-joke and joke meanings were activated at an equivalent high level during the incongruity stage and both showed reduced (but equal) activation immediately following presentation of the punchline.

\subsubsection{Discussion}

The present study addressed two questions: (1) whether joke meanings are activated gradually or suddenly and (2) whether, at the incongruity and/or resolution phases of joke processing, the initially favored, but non-joke meaning (S1) continues to be primed while the surprising but true joke meaning (S2) becomes activated.

With respect to the first question, our results are consistent with a sudden shift view, since S2 was not primed at the initial, setup stage but showed a high level of priming at the intermediary time point (incongruity stage). Our finding that joke priming was initiated well before resolution suggests that numerous potential scripts may be activated as soon as an incongruity is encountered. This may reflect an automatic spreading activation effect whereby there is increased activation of all concepts that could potentially be related to the surprising meaning. Alternatively, it could reflect a controlled, strategic search for alternative meanings. One way of testing the latter possibility in future research may be to examine joke processing under intentional vs. incidental conditions, or to vary the proportion of joke and non-joke stimuli. The question to be examined here would be whether, if all the stimuli presented are humorous, that would make the joke comprehender more inclined to explore less salient or alternative readings of texts more readily than if none or only some of the items were humorous.

With respect to the other central question in this study, namely whether there is concurrent or sequential meaning activation during joke processing, our results support a concurrent activation view. We found that S1 and S2 meanings were equally primed at the intermediary time point of joke texts (i.e. at the incongruity phase), ${ }^{4}$ and that they both continued to show equal activation (albeit at a lower level) at the final time point (punchline) as well.

While these results support a concurrent activation view up to the onset of joke resolution, a selective activation view is not ruled out. The latter view might charac-

\footnotetext{
3 Difference scores are represented here in positive numbers, but they actually refer to a decrease in response time from baseline.

4 It is important to note that the JavaScript programming language was used to devise the experiment, thus RT measurement precision was limited to within $1 / 100 \mathrm{~s}$. However, we are comfortable that the measures used give a satisfactory depiction of the overall pattern of results.
} 
terize what happens post-resolution; that is, if the final probe were presented somewhat later, one might find a relative decrease in activation of the initially favored meaning. This possibility was tested in the second experiment.

Our finding of reduced activation for both S1 and S2 meanings at the final time point relative to the two earlier points in the joke text is somewhat difficult to interpret. Could this be evidence of the 'double-take' moment experienced immediately upon delivery of a punchline? That is, does the relative decrease in activation reflect a momentary effect of response competition in working memory? An additional measurement point presented shortly after punchline offset could help clarify this result as well.

A related recent experiment on the time course of joke processing (Colston et al., 2000) also suggests the need for examining a later time point. In this study, joke priming was examined using a lexical decision priming procedure with self-paced reading of jokes and nonjokes displayed line by line on a computer screen. Lexical decisions were to be made for probes presented immediately after offset of each line. Word probes were either related to $\mathrm{S} 1$ or to $\mathrm{S} 2$, or were unrelated to either meaning (baseline). Consistent with our own results, Colston et al. found that probes related to S1 were primed after offset of the key word at the end of the first line (setup phase) and that priming was still marginally significant after offset of the second segment (incongruity). However, at the punchline position, the S1 was no longer more activated than the unrelated probe. Colston et al. (2000) interpret this absence of priming for the $\mathrm{S} 1$ at punchline in terms of a suppression effect. However, since the true joke meaning (S2) was also not primed at punchline (or earlier), a suppression explanation for the favored meaning may not be warranted. Moreover, if what is meant by suppression is inhibition, one would have expected a negative priming effect. Colston et al. suggest that the lack of priming of S2 may have been due to insufficient time for participants to process the intended meaning of the joke text.

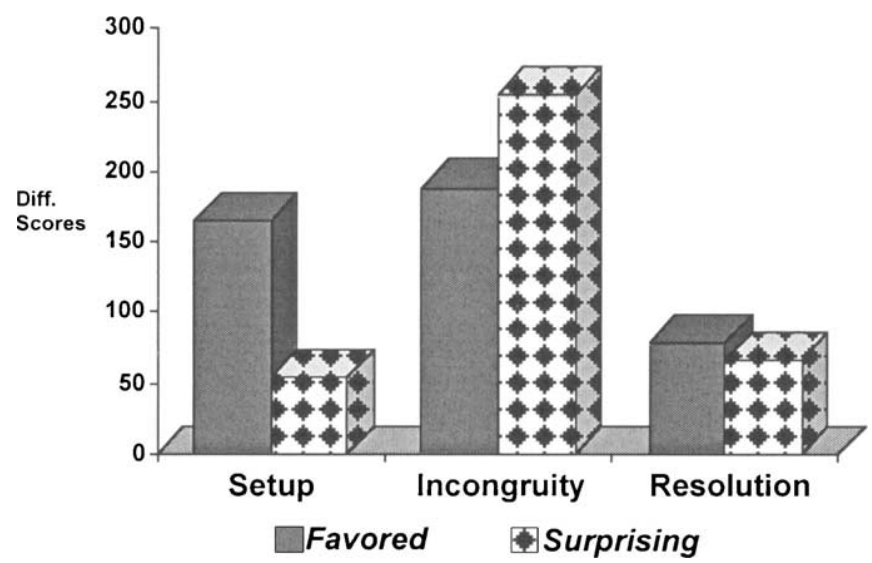

Fig. 1. Relative priming of joke scripts across time. 
In summary, both our results and those of Colston et al. (2000) point to the need for additional research on priming of joke meanings when the probe is presented well after participants have had time to process the intended joke meaning.

\subsection{Experiment 2}

Our second experiment was conducted to examine the fate of the initially favored meaning (S1) after additional time was provided for comprehension of the joke meaning. Priming effects in this experiment were examined using a design similar to that of Colston et al. (2000) in which lexical decision response latencies to S1 and S2-related targets were compared for one-liner jokes relative to neutral controls paired with each probe type. Unlike the previous experiments, priming in this experiment was studied only at the very end of the joke text. Joke stimuli (and non-joke fillers) were presented for $4500 \mathrm{~ms}$. It was hypothesized that, given that additional time was provided for the joke meaning to be fully processed, a priming effect should be evidenced only for $\mathrm{S} 2$, with the $\mathrm{S} 1$ being relatively less active.

\subsubsection{Method}

2.2.1.1. Participants. Participants were 77 college students from a southwestern university in the US. They were tested individually.

2.2.1.2. Stimuli and design. Stimuli consisted of 32 one-line jokes and 60 filler sentences. Of the 32 joke sentences, 8 were paired with S1-related target words, 8 with unrelated controls matched in length to the $\mathrm{S} 1$ target words, 8 with $\mathrm{S} 2$-related target words, and 8 with unrelated controls matched to the S2 target words. See Table 2 for an example of the joke stimuli and probes.

Of the filler sentences, 12 were paired with unrelated words chosen at random from Francis and Kucera (1982). The remaining 48 fillers were paired with nonwords. Nonwords were modifications of real words accomplished by altering one letter of a real word (e.g., HIRD) but following orthographic and phonological rules of English. The 92 sentences were combined in a pseudo-random order, which imposed the constraint that no more than three experimental conditions occurred consecutively. An additional set of 16 sentences (half related and half unrelated) served as practice trials.

Table 2

Experiment 2. Sample joke text and probes

Joke sentence: I went to a strip mall and found that everyone had clothes on. ${ }^{\mathrm{a}}$

Favored meaning-related: PLAZA

Favored meaning unrelated control: STAIR

Surprising (true joke) meaning-related: BARE

Surprising meaning unrelated control: BELT 
Each target word was assigned to one of four stimulus lists using a Latin square design. This procedure ensured that the experimental targets (related words and unrelated controls) were counterbalanced across the four lists, such that a given target appeared in only one condition on each list. ${ }^{5}$

2.2.1.3. Procedure. Participants were simply told that they were in a study investigating how people process sentences. Each trial consisted of an initial fixation stimulus that appeared on the computer screen for $250 \mathrm{~ms}$, after which there was a blank screen for $200 \mathrm{~ms}$ followed by presentation of the sentence (joke or filler), which was displayed all at once for $4500 \mathrm{~ms}$. A target stimulus (word or nonword) was presented in uppercase letters $150 \mathrm{~ms}$ after sentence offset and was displayed for $300 \mathrm{~ms}$. Lexical decision times (manual responses) were recorded in ms from target onset. There was a $3000 \mathrm{~ms}$ response window to allow subjects sufficient time to respond.

To ensure that participants were reading and understanding the sentences, a recognition task was given at the end of the experiment. The recognition task contained the same sentences that had been shown during the study and new sentences.

\subsubsection{Results and discussion}

Only mean responses to the joke target words were analyzed. A $2 \times 2$ within-subjects analysis of variance was performed with the factors being Probe Type (S1 vs. S2) and Probe Relatedness (semantically related word vs. unrelated control). Outliers, defined as responses that were 2.5 standard deviations above or below the mean, were removed from the dataset prior to data analysis. The analysis of variance revealed a significant effect of Probe Relatedness $[F(1,76)=8.53, P<0.004]$ : probes that were related to the joke text yielded shorter response latencies than probes unrelated to the joke text (724 vs. $743 \mathrm{~ms}$, respectively). Although there was no significant effect of Probe Type $(F<1)$ or interaction of Relatedness $\times$ Probe Type $(F<1)$, separate examination of the Probe Relatedness effect per Probe Type was undertaken.

The analysis of the S2 data showed a significant Probe Relatedness, or priming, effect $[F(1,76)=6.89, P<0.01]$. That is, the mean RTs for targets related to the $\mathrm{S} 2$ (joke) meaning were significantly faster than that for unrelated controls ( $720 \mathrm{vs} .742$ $\mathrm{ms}$, respectively). The corresponding analysis for the S1 data fell short of showing a significant priming effect $[F(1,76)=2.73, P=0.1]$ : the mean RTs for S1-related vs. unrelated targets were 727 vs. 744 ms, respectively; see Fig. 2).

To summarize, the results show that when subjects are allowed ample time to read joke texts, a priming effect is obtained, but the effect is reliable only for probes related to $\mathrm{S} 2$, the true joke meaning. Targets related to S1, the non-joke meaning, were not significantly faster than their matched neutral controls. Inasmuch as priming appeared to be somewhat greater to S1 than S2 target words, the results from this experiment support the selective activation view of Giora (1991), which predicts that the effect of the initially favored reading will be erased upon processing of the punchline, the true joke meaning.

\footnotetext{
5 This counterbalancing was done because, as Love and Swinney (1996: 15) point out, "it is standard procedure in psycholinguistic studies [to ensure] that no subject hear more than a single experimental sentence paired with more than a single visual probe in the study (to eliminate repetition-bias effects of any sort)".
} 


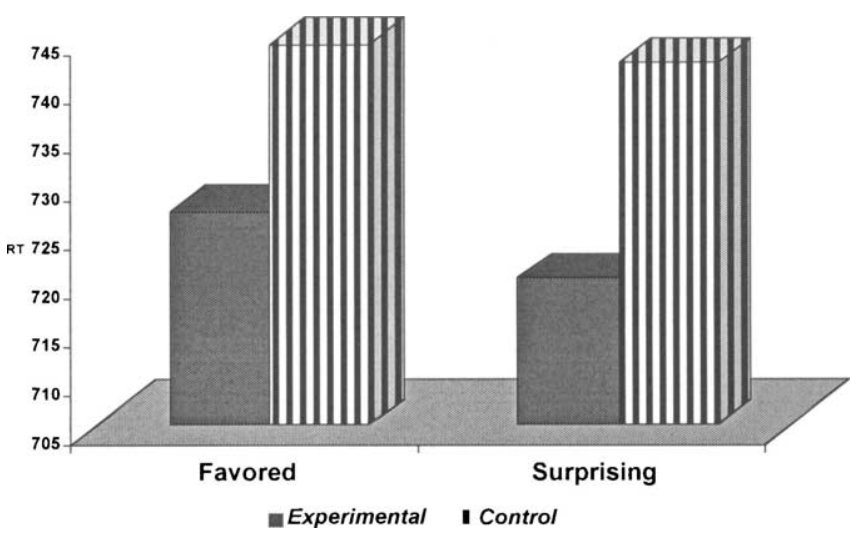

Fig. 2. Relative priming of joke scripts across conditions.

\section{General discussion}

The present research adapted a priming task commonly used in psycholinguistic research to study ambiguity resolution to explore the time course of activation of the two disparate meanings of joke texts - the sense initially favored by the context but that proves to be irrelevant to the intended meaning of the joke (S1), and the intended joke meaning (S2), arrived at after a conceptual frame shift or reanalysis of the original reading of the joke. Two semantic priming experiments were conducted in which probes related to one or the other meaning (or unrelated probes) were presented at different time points in the joke text.

Our first experiment found that S1 is selectively primed at an early point in the joke (corresponding to the setup phase) and that priming persists at an intermediary time point (corresponding to incongruity), even though the initial reading no longer makes sense by then. At the intermediary point, S2 becomes primed as well, and both meanings are concurrently active at a high level during the intermediary (incongruity) phase and at a reduced level at the final (resolution) phase. Our second experiment, in which one-line jokes were displayed for a longer viewing period (nearly 5 secs, as compared to $2500 \mathrm{~ms}$ per line in the previous experiment), showed reliable priming only for S2 at joke offset.

Taken together, our results support Attardo's (1997) and Nerlich and Clarke's (2001) concurrent activation view of meaning activation, at least up to a certain point in the processing of a joke text, i.e., from incongruity onset to resolution onset. Our results also corroborate and extend a pattern observed by Colston et al. (2000) in that at a later point in processing, S1 was no longer primed, whereas S2 continued to be primed. As such, our findings also support Giora's (1991) selective activation view, according to which only the true joke meaning would be primed after the joke is fully processed.

While our research points to a selective priming view of meaning activation upon completion of joke processing, more studies are needed to confirm our findings as well as to clarify the pattern we obtained and to broaden the scope of inquiry. 


\subsection{Caveats}

One possible limitation of our first experiment is that individual differences in overall reading time were not controlled for. Given that some joke lines were longer than others, it is possible that slower readers may not have had sufficient time to process the joke lines as compared to faster readers. A self-paced reading task, such as that used by Colston et al. (2000) would help address this potential artifact. By the same token, however, subjects allowed to self-pace may not be providing immediate reactions; rather, they may hesitate after reading the incongruity and/or the punchline to "figure out" the intended meaning before pressing the key that indicates they have finished reading the line. So self-paced presentation may be most appropriate for measures taken after joke offset. For earlier time points, the ideal situation would be to identify each individual's reading speed during practice trials, and then instantiate that rate for that subject during the experimental trials. Reading speed is unlikely to have affected the results of our second experiment, since participants were given a lot of time to read each stimulus sentence.

Another issue that is unclear from our study is the potential influence of differences in joke type, difficulty, and/or funniness. Presumably, jokes that are harder to figure out, for whatever reason, would slow down processing time. Since ratings of the jokes were not obtained, and since the jokes were not preselected to vary systematically, we are not in a position to comment on the potential effect of these stimulus-related variables.

\subsection{Further questions}

Although our findings suggest that joke processing involves selective activation of $\mathrm{S} 2$, the true joke meaning, relative to $\mathrm{S} 1$, the initially salient but ultimately irrelevant reading, many other questions still remain. An obvious question concerns the precise timing and duration of activation of S1 and S2. The lexical decision semantic priming procedure may not be an optimal method for studying the unfolding of joke meanings in real time; a more sensitive procedure may be a cross-modal lexical priming task (see Stewart and Heredia, 2002). However, both of these methods still require participants to be interrupted at different time points to make lexical decisions. Electrophysiological approaches, which simply monitor subjects' reading or listening while they are presented with a text, are perhaps better suited for studying the online processing of meaning activation in real time.

In a recent ERP study of joke comprehension, Coulson and Kutas (2001) found evidence for neural sensitivity to joke endings as early as $300 \mathrm{~ms}$ post-stimulus onset in normal readers, presented with identical sentences that ended in surprising but semantically congruent (non-joke) endings vs. joke endings that involved frame-shifting. In all participants, jokes elicited more negative ERPs 300-500 ms post-stimulus (particularly over left anterior sites) and particularly for items that had a high degree of semantic constraint. In low constraint sentences, joke endings showed more negativity over right posterior sites. Clearly, more work of this kind is needed to elucidate the chronology and topography of joke processing. A combined approach using ERP with eyetracking may be even more fruitful. 
It would be important for further research to investigate whether the initial reading of an ambiguity in a joke involves the salient or less salient meaning of the ambiguous expression. Given that research on the processing of lexically ambiguous words suggests that the more dominant meaning remains active for a longer period of time than does the less dominant meaning, one may examine whether this effect will also occur in the context of joke texts varying in the salience of the initial meaning. That is, if the $\mathrm{S} 1$ reading set up by the joke context is consistent with the dominant or salient meaning of an ambiguous key word in the joke, would this meaning persist even after it has been shown to be inappropriate?

Another question that could be explored is the role of individual differences in joke processing, specifically as these pertain to suppression skill. Suppression ability plays a crucial role in the understanding of metaphors, idioms, and proverbs (see Gernsbacher and Robertson, 1999, for a review); yet we are not aware of research that has studied it in the context of jokes. A further variable that may prove interesting in relation both to suppression skill and the time course of meaning activation in joke processing is that of bilinguality (Vaid, 2000; Vaid and Martinez, 2001). Might less proficient second language users be less able to suppress the irrelevant meaning of jokes presented in their second than in their first language? And how might humor that turns on word play across languages be processed?

Even in single language users, there may be differences related to joke comprehension ability per se. Coulson and Kutas (2001) found different patterns of neural response between good and poor joke comprehenders. For good joke comprehenders, the registration of surprise elicited late positivities at $500-900 \mathrm{~ms}$, whereas frame-shifting showed a sustained negativity 500-900 ms focused over left lateral electrode sites. Poor joke comprehenders in turn showed negativity over the right hemisphere. In what other ways might good and poor joke comprehenders differ?

It would also be interesting to explore the influence of set effects in meaning activation for ambiguous texts. That is, will expecting to hear/see humorous text make one more attuned to alternate readings earlier on in joke processing than if one does not expect to encounter humorous text? In other words, to what extent is meaning activation in joke processing subject to strategic control?

Finally, the scope of the presumed selective activation effect in joke processing needs to be studied further. Is selective activation restricted to jokes involving semantic ambiguity of a particular sort, i.e., where the joke meaning is completely unrelated to the initially favored meaning? Might selective activation of S2 and suppression of S1 meaning be more pronounced if the two readings of the joke involve homonyms, i.e., words that share a form but that differ in their meaning, than if they involve polysemous words or homophones (see Nerlich et al., 1998)? How might humorous riddles be processed? For example, in the riddle "Why does the teacher wear sunglasses? Because the class is too bright," (cited in Nerlich and Clarke, 2001) the humor seems to require that both meanings of 'class' (to mean room and students in the room) and of 'bright' (to mean sunlit and clever) be kept available in working memory to allow the humor to be enjoyed. And what about jokes in which irony is central? Would one still expect suppression of S1 for ironic humor? More generally, under what conditions might one not expect suppression of the non-joke meaning? Are there types of humorous discourse in which it is not 
appropriate to contrast joke and non-joke meanings since both meanings need to be activated in order to truly appreciate the intended humor of the joke? What are the cognitive and communicative conditions that favor a simultaneous or conjoint activation of multiple meanings in humor vs. conditions that promote selective activation of one at the expense of the other? Is the difference that Giora (1991) suggested between wit and humor (where wit sustains ambiguity but humor cancels it) the only way of conceptualizing differences, or can one allow for witty humor as well?

As should be clear from the above, much remains to be explored in the study of meaning activation in humor comprehension.

\section{Acknowledgements}

Portions of this research were presented at the annual meeting of the Psychonomics Society held in New Orleans, 2000, and in Orlando, 2001, and at the annual meeting of the Society for Computers in Psychology, held in New Orleans, 2000.

\section{Appendix A. Joke stimuli-Experiment 1}

Woman walks into a bar with a duck on a leash./ Bartender says 'Where'd you get the pig?'/ Woman says 'This is not a pig...it's a duck.'/ Bartender says 'I was talking to the duck.'

Man asks friend, 'How are women like department stores?'/ 'How's that?' the friend asks./ Man answers, 'Their clothes should always be half off!'

Man says, 'My wife is like plastic wrap.'/ 'How so?' asks his friend./ Man replies, 'She's cheap, clingy, and easy to see through.'

A senior citizen answers a call from his wife on his car phone./ His wife cries, "The news just said there's a car going the wrong way on 280; be careful./ Man says, 'Heck, it's not just one car. . .it's hundreds of them!'

Doctor calls patient and says, 'The good news is you have 24 hours to live.'/ Patient sobs, 'Then what's the bad news?'/ Doctor says, 'I forgot to call you yesterday!'

Man calls the hospital and says, 'You gotta send help! My wife's going into labor!'/ The nurse says, 'Calm down. Is this her first child?'/ Man yells, 'No! This is her husband!'

A little kid's in school taking a true-false test, and he's flipping a coin./ At the end of the test, he's flipping the coin again/. The teacher says, 'What are you doing?'/ The boy says proudly, 'Checking my answers!' 
God tells man, 'A million years is to me what a single second is to you.'/ God tells man, 'A million dollars is to me what a single penny is to you.'/ Man says, 'God, can I have one of your pennies?'/ God smiles and says, 'Certainly, just a second.'

\section{Appendix B. Joke stimuli-Experiment 2}

\begin{tabular}{|c|c|c|c|c|}
\hline Joke sentence & $\begin{array}{l}\text { Initial } \\
\text { meaning } \\
\text { related }\end{array}$ & $\begin{array}{l}\text { Initial } \\
\text { meaning } \\
\text { control }\end{array}$ & $\begin{array}{l}\text { Joke } \\
\text { meaning } \\
\text { related }\end{array}$ & $\begin{array}{l}\text { Joke } \\
\text { meaning } \\
\text { control }\end{array}$ \\
\hline $\begin{array}{l}\text { I tried to sniff Coke, but the ice } \\
\text { cubes got stuck in my nose. }\end{array}$ & Drug & Tail & Soda & Liar \\
\hline $\begin{array}{l}\text { Animal testing is terrible because } \\
\text { they get nervous and give wrong } \\
\text { answers. }\end{array}$ & Ethics & Brass & Intelligence & Comparison \\
\hline $\begin{array}{l}\text { Everybody has a photographic } \\
\text { memory, most just don't have film. }\end{array}$ & Recall & Finish & Camera & License \\
\hline $\begin{array}{l}\text { I asked if eating pie was } \\
\text { customary and the waiter } \\
\text { said it was apple. }\end{array}$ & Tradition & Discussion & Crust & Yodel \\
\hline $\begin{array}{l}\text { I asked if I was a gifted child } \\
\text { and dad said We wouldn't have } \\
\text { paid for you. }\end{array}$ & Smart & Lucky & Free & Real \\
\hline $\begin{array}{l}\text { I love cats because they taste } \\
\text { just like chicken. }\end{array}$ & Pet & Ace & Food & Earth \\
\hline $\begin{array}{l}\text { I no sooner get the closet of my } \\
\text { dreams then my husband comes } \\
\text { out of it. }\end{array}$ & Hanger & Hearse & Homosexual & Honeybee \\
\hline $\begin{array}{l}\text { I still miss my ex but my aim is } \\
\text { getting better! }\end{array}$ & Love & Court & Hate & Ease \\
\hline $\begin{array}{l}\text { I taught my dog to beg and last } \\
\text { night he came home with a few } \\
\text { dollars. }\end{array}$ & Trick & Stove & Ask & Army \\
\hline $\begin{array}{l}\text { I tried switching to gum but } \\
\text { couldn't keep it lit. }\end{array}$ & Bubble & Inning & Cigarette & Cocktail \\
\hline $\begin{array}{l}\text { I want to die in my sleep like } \\
\text { Grandpa but not screaming like } \\
\text { his passengers. }\end{array}$ & Peace & Near & Wreck & Notify \\
\hline $\begin{array}{l}\text { I went the extra mile, but my } \\
\text { boss found me and brought } \\
\text { me back. }\end{array}$ & Excel & Hoist & Distance & Standard \\
\hline $\begin{array}{l}\text { I went to a strip mall and found } \\
\text { that everyone had clothes on. }\end{array}$ & Plaza & Stair & Bare & Belt \\
\hline
\end{tabular}


I would like to help you out, which way did you come in?

If you have computer problems check for loose nut in front of keyboard.

I've loved the same woman for years, if my girl finds out, she'll kill me.

Joe made all his money with crooked dough, as a pretzel maker.

Karen is like plastic wrap, cheap, clingy and easy to see through.

Mike's brother is at Penn State and John's brother is at State Penn too.

My card was stolen, but the thief is spending less than us.

My CHECK ENGINE light came on, but the engine was still there.

My church accepts any denomination but they prefer twenties.

Practice safe eating by using condiments.

Sex on television can't hurt you unless you fall off.

Some can tell time by looking at the sun, but I can't make out the numbers.

Sometimes I wake up grumpy but most times I let him sleep.

Sticks and stones may break my bones, but whips and chains excite me.

Sue will buy anything marked down, she even bought an escalator once.

The old man wondered why the toothpaste wouldn't make his teeth stick.
Assist

Repeat

Dismiss

Embark

Bolt

Ally

Crazy

Bent

Affection

Aluminum

Affair

Branch

Fraud

Junk

Baker

Error

Kitchen

Officer

Behavior

Approach

University

Military

Prison

Muscle

Crook

Hoop

Budget

Formula

Trouble

Influence

Search

Escape

Religion

Decision

Currency

Period

Manners

Operates

Protection

Electric

Netwo

Medicin

Furniture

Mystery

Shadow

Outlook

Bright

Touch

Mood

Noise

Dwarf

Chalk

Pain

King

Pleasure

Portion

Sale

Cast

Direction

Student

Brush

Agent

Glue

Arcs 
Tom says, My wife's an angel, and $\mathrm{Jim}$ responds his is still alive.
Nice

Fashion
Rich

Heaven

Lawyer

Women are like department stores, their clothes should always be half off.

\section{References}

Attardo, Salvatore, 1997. The semantic foundations of cognitive theories of humor. Humor 10, 395-420. Attardo, Salvatore, Raskin, Victor, 1991. Script theory revisi(it)ed: joke similarity and joke representation model. Humor 4, 293-347.

Colston, Herbert L., Giora, Rachel, Katz, Albert 2000. Joke Comprehension: Salience and Context Effects. Paper presented at the 7th International Pragmatics Conference, Budapest.

Coulson, Seana, 2001. What's so funny: conceptual blending in humorous examples. In: Herman, V. (Ed.), The poetics of cognition: studies of cognitive linguistics and the verbal arts. Cambridge University Press, Cambridge.

Coulson, Seana, Kutas, Marta, 2001. Getting it: human event-related brain response to jokes in good and poor comprehenders. Neuroscience Letters 316, 71-74.

Francis, Winthrop Nelson, Kucera, Henry, 1982. Frequency Analysis of English Usage: Lexicon and Grammar. Houghton Mifflin, Boston.

Gernsbacher, Morton Ann, Robertson, Rachel, 1999. The role of suppression in figurative language comprehension. Journal of Pragmatics 31, 1619-1630.

Giora, Rachel, 1991. On the cognitive aspects of the joke. Journal of Pragmatics 16, 465-485.

Giora, Rachel, in press. On Our Mind: Salience, Context, and Figurative Language (chapter 6), Jokes. New York: Oxford University Press.

Kittay, Eva, 1987. Metaphor: Its Cognitive Force and Linguistic Structure. Clarendon Press, Oxford.

Koestler, Arthur, 1964. The Act of Creation. MacMillan, New York.

Love, Tracy, Swinney, David, 1996. Co-reference processing and levels of analysis in object-relative constructions: demonstration of antecedent reactivation with the cross-modal priming paradigm. Journal of Psycholinguistic Research 25, 5-24.

Nerlich, Brigitte, Clarke, David D., 2001. Ambiguities we live by: towards a pragmatics of polysemy. Journal of Pragmatics 33, 1-20.

Nerlich, Brigitte, Todd, Zazie, Clarke, David D., 1998. The function of polysemous jokes and riddles in semantic development. Cahiers de Psychologie Cognitive. Current Psychology of Cognition 17, 343365.

Norrick, Neal R., 1986. A frame-theoretical analysis of verbal humor: bisociation as schema conflict. Semiotica 60, 225-245.

Raskin, Victor, 1985. Semantic Mechanisms of Humor. Kluwer Academic, Dordrecht.

Stewart, M., Heredia, Roberto, 2002. Comprehending spoken metaphoric reference: a real-time analysis. Journal of Experimental Psychology 49, 34-44.

Suls, Jerry M., 1972. A two-stage model for the appreciation of jokes and cartoons: an information processing analysis. In: Goldstein, J., McGhee, P. (Eds.), Psychology of Humor. Academic Press, New York, pp. 41-45.

Vaid, Jyotsna, 2000. New approaches to conceptual representations in bilingual memory: the case for studying humor interpretation. Bilingualism. Language and Cognition 3, 28-30.

Vaid, Jyotsna, Martinez, Francisco, 2001. Figurative Language and Thought Across Languages: What Transfers? Poster presented at the 3rd International Symposium on Bilingualism, Bristol.

Vaid, Jyotsna, Ramachandran, Vilayanur S., 2001. Laughter and humor. In: Blakemore, C., Jennett, S. (Eds.), Oxford Companion to the Body. Oxford University Press, Oxford, pp. 426-427.

Veatch, Tom C., 1998. A theory of humor. Humor 11, 161-215. 
Jyotsna Vaid is a professor of psychology at Texas A\&M University. Her primary research is on psycholinguistic and neuropsychological aspects of language and literacy in bilinguals. In addition, she has conducted research on cognitive bases of humor and proverb comprehension and has authored reviews of the brain bases of bilingualism (with Rachel Hull) and of neural approaches to humor. She has also edited Language Processing in Bilinguals (Erlbaum), co-edited Creative Thought: An Investigation of Conceptual Structures and Processes (APA), and is co-editing a special issue of Reading and Writing, forthcoming, on syllabic and semi-syllabic scripts.

Rachel Hull is a doctoral candidate in psychology at Texas A\&M University. Her master's thesis was an empirical study of cognitive processes in humor generation. She has also conducted a meta-analytic review of cerebral laterality research on bilinguals, and is the author (with Jyotsna Vaid) of a chapter in Advances in the Study of Neurolinguistics (Udine University Press) and a chapter in The Handbook of Bilingualism: Psycholinguistic Aspects (forthcoming, Oxford University Press).

Roberto R. Heredia is an assistant professor of psychology at Texas A\&M International University. His research focuses on understanding the basic processes of language comprehension, specifically sentence processing and lexical access, ambiguity resolution and the comprehension of nonliteral language in both bilinguals and monolinguals. He has published research articles in bilingual memory representations, nonliteral language, and stereotype processing from a figurative language perspective. He is presently guest editor for the journal, Experimental Psychology, and co-editor of a forthcoming volume on Bilingual Sentence Processing.

David Gerkens is a doctoral candidate in psychology at Texas A\&M University with research interests in memory and problem solving. Specific interests include false memories and blocked and recovered memories, as well as the development of web-based methodologies for data collection. His master's thesis was concerned with properties of memory for prose.

Francisco Martinez is a master's candidate in psychology at Texas A\&M University. His research interests are on psycholinguistic approaches to bilingual lexical and sentence comprehension, with a focus on nonliteral language. He has conducted a study on the processing and representation of proverbs in SpanishEnglish bilinguals. 